\title{
Drug Abuse in Italy and Europe in a Comparative Context
}

\author{
by Mario Garavelli*
}

\section{The Problem of Drugs}

The definition of a "drug" put forth by the World Health Organization is any chemical substance, natural or artificial, that modifies the psychology or mental activity of human beings. The equivalent scientific term is "psychoactive substance." Drugs have been used for centuries, ${ }^{1}$ and the use to which drugs such as coca, hashish, and opium have been put has been a part of ancient cultures as well as a way of life for many populations. However, it has only been since the last century that this use has become such a serious problem throughout the world for many individuals and for society as a whole. Nowhere is this use more of a problem than in the industrialized nations.

Drug usage has diffused through many strata of the world's population and into anthropological contexts which are unable to regulate the use of drugs. The consequences of this more widespread usage have been (1) a decrease of participation in normal social activities by young people, (2) an outbreak of minor crimes linked to the purchasing of these substances, (3) development of criminal organizations which have realized enormous profits in the drug trade, and (4) more recently, an increase in the spread of AIDS.

The factors which lead to this abnormally high drug consumption throughout the industrialized world are analogous from country to country. The significant factors include more comprehensive welfare programs, improvements in communications and transportation, the slackening of moral values together with an added emphasis on "consuming," and the institutional pressures of family and school. ${ }^{2}$

This Article does not address the medical, sociological, or criminological aspects of drug usage. Rather the focus is upon the main

* Presidente di Dipartimento di Corte di Appello, Torino, Italy (Judge, Court of Appeals, Turin, Italy).

1. Brian Inglis, The Forbidden Game: A Social History of Drugs (1975).

2. David T. Courtwright, Dark Paradise: Opiate Addiction in America BEFORE 1940 (1982). 
characteristics of the various drug control laws in the major European countries, especially Italy. Parallels with the drug abuse problem in the United States are drawn where appropriate.

\section{Common Themes in the Drug Use Laws of the World}

Due to inherent differences among cultures, legal systems and socio-economic situations of the nations of the world, an analysis of drug control laws reveals constants which are necessarily contrasted against a varied background. One of the most important constants in all drug control laws is prohibitionism. This is a universally accepted principle according to which the non-therapeutic use of narcotic substances is forbidden and sanctioned.

Prohibition is not the only possible answer to the problem of drug abuse in society; it is in part a natural reaction to a socially negative phenomenon. However, prohibitionism also has a definite historical dimension which can be linked to the prevailing ideology in the United States. This ideology has been forced upon other countries due to the weighty American influence on international organizations. ${ }^{3}$

The origins of prohibitionism can be traced back to 1600 in Turkey and Persia where tobacco consumers were put to the pillory. Later, in 1792, a Chinese law condemned opium sellers to strangulation. It was not, however, until the eighteenth and nineteenth centuries that the prevailing Protestant morals gave birth to the temperance movement which resulted in the first anti-alcohol laws in the States of New York (1845) and Maine (1851). The American Prohibitionist Party was created in 1869 and gained its first seat in the U.S. House of Representative in 1890. One of that party's objectives was the prohibition of alcoholic beverages, which was realized with the passage of the Volstead Act of 1920. This Act was repealed in the 1930s during the Roosevelt administration.

Similarly, in 1914, with passage of the Harrison Act, trade in and the use of opiates was forbidden. This same provision was put forth internationally for the first time in 1912 under the Aja Convention. ${ }^{4}$ From then on, the role of the United States in this area has been predominant, which in turn explains why prohibitionism has been accepted as an unquestioned postulate in facing the drug problem.

3. Charles R. Carroll, Drugs in Modern Society (2d ed. 1989).

4. Stanton Peele, The Meaning of Addiction: Compulsive Experience and ITS INTER PRETATION (1985). 
This univocal answer to the drug problem did not prevent the birth, in several countries, of anti-prohibitionist movements. The purpose behind the movements was to faciliate discussion of these absolutist ideas. Such movements point out the inability of prohibition to reduce the widespread increase in drug abuse. In addition they ask for replacement of prohibitionary policies with less severe measures. These measures fall into two categories: the first is liberalization which proposes the removal of every prohibition and absolute freedom of trade and consumption; the second is legalization which postulates that distribution should be controlled by governing bodies under particular conditions. ${ }^{5}$

These differing approaches, though still not widely accepted internationally, have already had some effect on legislation and legal practices in several countries. Therefore, it can be said that another constant theme in world drug policy is mitigation of prohibitionism. This mitigation can occur through limiting the types of substances prohibited, such as products derived from cannabis indica, or through consumer health policies, such as regulation of legal administration of methadone or morphine.

A final constant theme pertains to the treatment of drug addicts on an individual basis. The majority of laws with these provisions are aimed at medical and psychological treatment of drug addiction. Very often, the drug addict's illegal activities are not prosecuted if the addict makes a strong personal commitment to rehabilitative treatment.

\section{International Conventions}

The constants found in various countries of the world mentioned above, derive their principle justification from the long series of international agreements on drug policy. These agreements bind all the major states and set forth the directives and guidelines which the contracting states are bound to follow. The most important of these documents are outlined below. ${ }^{6}$

\section{A. The Conventions in Brief}

\section{Aja Convention (1912)}

The signing parties, in a limited number, agreed to regulate the production and distribution of raw opium and medical products derived

5. Andrew Sinclair, Era of Excess: A Social History of the Prohibition Movement (1962).

6. W. Wenawski, Drug Abuse Prevention: Recent International Efforts, in 3 EuroCRIMINOLOGY 13-26 (1990). 
therefrom, and to prohibit trade in treated opium used for non-medical purposes.

\section{Geneva Convention (1931 and 1935) ${ }^{7}$}

The representatives of 57 nations decided to control artificially produced drugs and to limit their use only to medical purposes. International cooperation in the prosecution of drug dealers was promoted, as was further specialization of narcotics divisions within enforcement agencies.

\section{Single Convention on Narcotic Drugs, New York $(1961)^{8}$}

Originally adopted by 70 nations, this convention was later ratified by 133 , and has become a model for anti-drug policies, having been integrated by a Geneva Protocol in 1972. Its purpose is to replace all previous agreements and to impose a general and absolute prohibition on all known drugs, extending to cannabis cultivations. It also set a deadline to prohibit the use of cannibus cultivations and coca in the countries where it was traditionally used.

This convention regulates in great detail the production and trade linked to prohibited substances. Article 36 provides for an "adequate punishment, particularly with detaining penalties" for serious crimes dealing with every activity linked to drugs. Thus, this convention asserts the universality of prohibitionism and states for all countries, including those who did not sign it, the obligation to fight against production of illicit drugs within their own territories.

This is also the first convention to address treatment for drug addiction. Article 38 obliges the contracting parties to "treat drug addicts and guarantee their rehabilitation."

\section{Convention on Psychotropic Substances, Vienna $(1971)^{9}$}

This convention includes a list of generally forbidden substances such as hallucinogens, amphetamines, THC, and barbiturates. It also provides detailed rules for their use in medical prescriptions and therapy.

7. League of Nations, Record of the Conference for the Limitation of the Manufacture of Narcotic Drugs, Geneva May 27th to July 13th 1931 (Volume 1: Plenary Meetings, Text of the Debates).

8. Single Convention on Narcotic Drugs, New York, March 1961, 18 U.S.T. 1407, T.I.A.S. No. 6298, 520 U.N.T.S. 204.

9. Convention on Psychotropic Substances, Feb. 21, 1971, 32 U.S.T. 543, T.I.A.S. No. 9725,1019 U.N.T.S. 175. 
5. Convention Against the Illicit Traffic of Narcotic Drugs, Vienna $(1988)^{10}$

This is the latest agreement which has inspired the most recent international laws. It was ratified by 50 nations in October 1991. Article 2 states the purpose of the convention as the promotion of cooperation among nations in drug policy. Article 3 provides:

1) that the parties deem not only the production and trade of drugs, but also their possession and purchase as penal violations if the latter are done with the intent to deliver the drugs to other people;

2) that, the organization and financing of such activities, along with the use or conversion of profits derived therefrom, be deemed penal violations;

3) that the possession of drugs for personal use be in and of itself a crime, but that together with punishment therefor, social and rehabilitative treatment measures must be adopted; and

4) that similar measures can replace penal sanction when "minor violations" occur.

\section{B. The Conventions Analyzed}

From a close analysis of these agreements, identification of the most important characteristics of international drug policy is possible. First, there is an ever increasing commitment to cooperation, especially among consumer states, which are most interested in limiting drug usage and which are also the most wealthy and influential of nations. This cooperation is evidenced not only in judicial rules such as the extradition and the mutual legal assistance provisions of Articles 6 and 7 of the Vienna Convention of 1988, but also in the close relationships among different police forces which have made the arrest of major drug dealers possible.

Second, there is a general consensus that the drug addict is an afflicted person in need of treatment and support rather than an antisocial person who must be punished. Consequently, this trend has resulted in increased attempts to provide new approaches to treatment in several different countries.

Third, the increase in international agreements on drug policy creates a greater homogeneity among various national drug policy laws.

10. Conventions Against the Illicit Traffic of Narcotic Drugs, Vienna, Dec. 19, 1988, U.N. Doc. E/CONF. 821/15 (1988). 
This is true both of the content and of the language of national drug policy laws. Therefore, comparative study of the laws themselves becomes easier and cross-national analysis of the effect of similar laws is possible.

Fourth, the increasing commitment to drug control in the international community has resulted in the creation of numerous organizations formed to deal with the drug problem. In addition to specialized institutions such as the U.N.O. agencies, ${ }^{11}$ various supranational bodies ${ }^{12}$ have come into existence along with private bodies, such as the Drug Policy Foundation in Washington D.C., the Italian Lega Internazionale Antiproibizionista, and the French Observatoire Geopolitique des Drogues. ${ }^{13}$

\section{European Legislation}

The European approach to drug policy presents several substantial uniformities. Most European countries promote a high degree of welfare, are industrialized, and are highly urbanized. These are all conditions which favor excessive consumption of everything, including drugs and alcohol. These common characteristics explain the profound similarities in the various national drug control laws.

Despite these similarities, the nations of Europe have developed separately in the context of their own judicial systems and social conventions; thus, original approaches have developed to face the drug problem in a common field which remains uncertain and difficult to understand. ${ }^{14}$ The final analytical portion of this Article is dedicated to a comparative study of different drug control laws of various European nations, together with a view of their particular features, and some applications where appropriate, with an emphasis in Italian drug policy.

\section{A. Italy}

The Italian drug law of 1975 was advanced for its time and was in line with the current scientific knowledge available. ${ }^{15}$ This law pro-

11. Some organizations are the followings: Commission on Narcotic Drugs; International Narcotic Control Board; World Health Organization; United Nations Fund for Drug Abuse Control; Division on Narcotic Drugs; United Nations International Drug Control Program.

12. Examples are the European Committee to Fight Drugs (CELAD), Interpol, and the World Health Organization.

13. They are called by U.N.O. "Non-Governative Organizations" (ONG). There is a large number of them, about 400 in Bolivia alone, for example.

14. A. Dervaux, Le Phénomène des Toxicomanies au Traver du Developpement des Legislations InTERnationales Specifiques (1988).

15. G. Ambrosini, Le Sostanze Stupefacenti (1989). 
vided for impunity of a person who committed crimes connected with drugs who was found in possession of a "moderate amount" of drugs not intended for sale. It also provided for imprisonment of up to 15 years

The law included a series of rules, based on French law, aimed at treating drug addicts who were to be sent to the National Health Service by court order. The ideology underlying this portion of the law was derived in part from viewing drug addicts as afflicted people in need of treatment. Also influential were the the Catholic Church and the political left which were more inclined to sympathize than to repress.

As the drug problem increased, public alarm and a change in the cultural environment occurred, making the faults of this law become more apparent. It was deemed too tolerant, and the social services that it provided were scarcely put into practice. These criticisms generated strong disagreements among the voluntary organizations, especially Catholic ones, which were very active with various juvenile problems in hundreds of communities.

The major principle of the 1990 law $^{16}$ that replaced the 1975 law is stated in Article 72: "The personal use of drugs is forbidden." From this prohibition, which had never previously been expressly declared, a series of non-penal measures emanated. These measures were intended to punish only non-serious violations of this provision. A non-serious violation is possession of a moderate amount of an illegal drug, known as the "average daily dose." The rationale for classifying the average daily dose as a non-serious violation is that it is probably only used by the possessor.

The range of punishments available under the law for a non-serious violation include suspension of driver's license, house arrest during the night or periodic check-in at the police station, prohibition from frequenting public places, and the impounding of private vehicles. These punishments are preliminarily ordered by the Prefect, an Italian government official, for the first two violations, and subsequently by the Pretore, the judge, after the filing of a police charge and a meeting with the defendant.

Although this enforcement procedure only punishes drug abusers with light penalties for personal use, the penalties are designed to create problems in their day-to-day lives. However, when the amount of the illegal drug possessed is greater than the average daily dose, its intended

16. Id. 
sale is presumed and the traditional criminal penalties are applied. This double-standard based on the amount of illicit drug possessed is intended to pressure simple drug addicts to enroll in specialized drug treatment centers for detoxification.

A rehabilitation feature of this new law provides for strengthening public services designed to curb drug abuse by creating treatment centers in every region within the National Health Service system. The goal is to help drug addicts by making available adequate personalized recovery programs which can vary from detoxification to placement in a recovery community to psychological treatment. Immunity from prosecution for those arrested and immunity from sentencing for those found guilty of crimes linked to drug addiction, such as theft or petty solicitation of illegal drugs, is offered for those willing to participate and complete one of the rehabilitation programs.

The law also focuses on both prevention through education and deterrence through punishment. Prevention through education is conducted through informational campaigns in school and during compulsory military service for men in the Italian military. Deterrence through punishment has resulted in a notable increase in punishment for crimes linked to drugs. Article 73 provides for imprisonment of eight to 20 years and heavy fines for possession and sale of large quantities of illegal drugs. Imprisonment of one to six years is mandated for possession and sale of small quantities of illegal drugs.

The innovative approaches of this comprehensive law have produced mixed results. While the number of people assisted by social services has increased, the number of people imprisoned has also increased to the point that the jails have become overcrowded. Over 50,000 prisoners, many of whom are drug addicts, populated the 35,000 available places in the Italian prison system as of the spring of 1993 . This crisis led to a referendum of the new law by the people who voted in favor of cancelling that portion of the law that dealt with punishment of drug consumers.

The direct effect of this vote was the removal of both the prohibition expressed in Article 72 and the average daily dose limit that, if exceeded, made those who possess illegal drugs for personal use punishable with jail sentences. Now, simple possession of a moderate but undefined dose of an illicit drug is only punishable by minor sanctions ordered by the prefect, such as suspension of one's driver's license or passport. The most serious sanctions, previously ordered by the judge, have disappeared.

Consequently, the current situation is very uncertain since any drug possession can be punished only if there is concrete evidence of 
its destination for trade or if the judge believes that such a purpose is likely based on the amount of the drug involved. Italy awaits legislative intervention or the creation of a uniform jurisprudence which provides the Courts with reference parameters. However, the will of the Italian people, as expressed in the referendum, was certainly in favor of at least the possibility of punishment for drug addicts.

\section{B. France}

The French law of December 31, 1970, as amended in 1987, provides for penalties of up to one year in jail for possession of illegal drugs and prison sentences ranging from two to ten years for trade in illegal drugs. Under aggravating circumstances, these sentences may be raised to 20 years for illegal drug trade.

For the drug addict arrested for possession, the French judge can order compulsory recovery treatment which stops the penal action if accepted. This forced rehabilitation is found in Article L355 of the French law which provides that "all those who illicitly use substances classified as drugs are placed under the surveillance of the Health authorities." 17

With a view toward strengthening the fight against AIDS, the sale of sterile syringes was liberalized in 1988. Thus, the network of services offering various intervention models has been strengthened to include welcome centers, specialized hospital units, and therapeutical communities. $^{18}$

\section{United Kingdom}

The Misuse of Drugs Act of 1971, followed by the Misuse of Drugs Regulation of 1973 and the Misuse of Drugs Order of 1977, classifies drugs into three categories: (1) cocaine and opiates; (2) cannabis and hallucinogens, barbiturates, amphetamines; and (3) pharmaceutical.

The penalties against trafficking of drugs are very severe, from life imprisonment in the most serious cases to seven or 14 years respectively for illegally selling drugs from categories one and two above. Penalties for possession are severe also, with possible sentences of up to 14 years for possession of "heavy" drugs. However, as in Ireland,

17. Translation by the author.

18. C. Trautmann, Rapport au Premier Ministre sur la Lutte Contre la Toxicomanie et la Trafic de Stupefiants (1989). 
personal use is prohibited only in the case of opium. The use of other drugs is therefore practically permitted.

Therapeutic rehabilitation treatment is enforced under this law. The treatment is administered by ${ }_{\sigma}$ regional authorities which make use of special assistance services coordinated by the "District Committees for Counseling about [the] drug problem." The physician who deems that one of his patients is a drug addict is required to inform the health authorities.

\section{Germany}

The drug control law of 1971 , as updated on July 28, 1981, punishes the illegal circulation of drugs with imprisonment from three to ten years, which may be raised to 15 years in the case of organized crimes. The judge, however, can omit the penalty "if the guilty person holds drugs for personal use in a minimum amount," and can impose rehabilitation treatment. Even a final sentence of less than two years for crimes connected to drug addiction can be exchanged for therapy.

The network of services pertaining to a single state (Land) is expanding to include varied methods of treatment. The distribution of synthetic substances, such as L-Palamidon, is also more widespread in Germany under this law.

\section{E. Spain}

From the drug control laws of 1976 and 1983, Spain has moved to the law of March 24,1988, which states that the use and detention for personal use of illegal drugs is not punishable. The penalties vary from two to eight years imprisonment for the production and trafficking of "heavy" drugs and from four months to four years for the production and trafficking of "light" drugs. However, if a criminal organization is involved, these sentences may be increased to 23 years.

The Spanish law also allows for suspension of up to two years of punishment if a therapeutic rehabilitation program is accepted by the defendant. Compulsory treatment and the restriction of freedom of movement in the form of house arrest or driver's license suspension for dangerous drug addicts are other options which the court may order.

\section{F. Holland}

The Dutch system provides that even if possession of drugs for personal use is formally considered a crime under the May 12, 1928, drug control law, as modified in 1976 and 1985, this use in the case of "light" drugs is not punished because of the ability of the State 
Attorney to decline initiation of criminal proceedings. However, drug trafficking is punished with imprisonment of up to twelve years for "heavy" drugs and up to four years for "light" drugs.

The network of assistance services is broad and efficient, even if treatment is voluntary. Sterile syringe distribution, drug addiction control, and streetside mobile units for public assistance have all been employed to combat the expansion of the AIDS virus.

\section{G. Sweden}

Penalties for crimes connected to drug trafficking in Sweden are very light: imprisonment up to three years for serious crimes and up to six months for non-serious crimes. Under the amended law of June 1968, penalties may be increased to ten years for serious crimes involving large amounts of drugs, organized crime, or "particularly dangerous" criminals.

Personal consumption is practically immune from criminal punishment. Instead, the government uses pecuniary sanctions and drug exchanges; when "the event is not serious," the suspects are free from punishment. Under law 870 of 1988 , the Prefecture can request the county court to order the forced treatment of drug addicts. This treatment is offered through special institutions managed by local administrations or local governments. Upon commencement of treatment, the Public Prosecutor may forfeit proceedings against guilty persons for their minor crimes.

\section{H. Other Countries}

With minor differences in the length of penalties available, the legislation of other European states provides for various forms of punishment for drug trafficking which can be severe; but therapy for drug addicts is also universally offered or mandated. Greece, Malta, Cyprus, and Portugal use long penalties of up to 14 or 20 years imprisonment for drug trafficking, while Austria, Luxembourg, and Switzerland have much shorter drug trafficking penalties of three to five years. Penalties in Norway range from only 14 days to a lengthy 21 years in the case of "heavy" drug trafficking or money laundering.

Most of the laws regulate the treatment of drug addicts explicitly. Generally, the Northern countries, apart from Sweden and Ireland, tend to leave it to the choice of the defendant, while the other countries require compulsory treatment.

\section{Conclusions}

This brief, comparative overview of European drug control law enables one to identify the main trends in legislative policies regarding 
this topic within Europe. The international community, through conventions, continues to support the prohibition alternative; thus in Europe, drug trafficking and consumption are theoretically punishable. European countries punish major and moderate dealers with several years imprisonment, while the principle of lesser punishment for less serious crimes remains prevalent.

The laws of the Mediterranean countries, together with Ireland, tend to be the sternest ones. Conversely, the drug phenomenon is perceived as less alarming in the Scandinavian countries where alcoholism is believed to be a more serious social problem.

However, a sign that the general public perceives the drug abuse problem as more dangerous than other social problems is the increasing pressure on legislatures to modify their laws with more consideration for the drug addict as a person. This perhaps stands in opposition to popular sentiment regarding various other strict laws punishing criminal acts or asocial conduct such as prostitution, alcoholism, or juvenile crimes.

The illegal use of drugs is formally forbidden in France, Luxembourg, and Italy where it was subsequently cancelled by referendum. Collective use is forbidden in Belgium. In Ireland and the United Kingdom, only the use of opium is officially forbidden. To the contrary, Spain and Holland allow the use of opium, and it is de facto tolerated in Belgium, Denmark, Germany, Portugal, the United Kingdom, and now Italy. However, some countries still punish for purchasing opium, or, as in the case of Portugal, possession.

All Western European nations consider drug addicts responsible for their actions except Greece, which frees them from penal proceedings but subjects them to compulsory therapy. However, this provision of the Greek law only applies to those addicts whom the law defines as people accustomed to drugs and incapable of giving them up without therapy, while other addicts are subjected to the penal law.

Even if all of the laws specifically regulated the methods of treatment, they would still be divided between the majority that espouse the efficacy of compulsory treatment under the intervention of judicial authority, as in France, Greece, Ireland, Spain, Sweden, Luxembourg, and Portugal, and the minority of laws which leave it to the drug addict's free will. However, the latter almost always reduce this freedom of choice by offering the addicts the alternative between either penal or administrative punishment and the acceptance of a therapeutic rehabilitation program.

The universal result under both types of law is strengthened public services in drug control everywhere and increased cooperation with 
numerous private charitable bodies pursuing the same goals. The Italian law is perhaps the most explicit in this regard since it allows for public bodies to make agreements with private ones for funding these programs.

In Canada, the drug control law of 1970 , which strictly punishes drug trafficking, only imposes a fine for personal use and does not provide for alternative therapeutic measures. In the United States, the federal law of 1988 imposes important directives in the context of the "war on drugs" proclaimed by the Omnibus Act of 1986. The introduction of the death penalty for major drug dealers, together with a sanction of up to $\$ 10,000$ for the personal use of drugs, are some of the most stringent measures. There has been a great effort exerted toward the prevention of drug use, especially in the workplace. ${ }^{19}$

The European situation is characterized not only by the distinct efforts of the different legislatures, but also by a series of attempts to ascertain the difficulty of reducing the problem through suppression of drug usage and the probability of success in the short term. The theory thus derived is that of "harm reduction" which recognizes that the acceptance of drugs in the social context is unavoidable. Thus, it becomes necessary to concentrate on the search for alternative methods of reducing the harmful effects of drug usage.

Attempts in this direction have been varied and diverse. For a long time in Zurich, Switzerland, drug addicts were confined to the town park and allowed to consume drugs there. However, the degeneration of the situation obliged the city to eventually close the park. In Holland, Liverpool, Berne, and Frankfurt, ${ }^{20}$ there are currently programs in place to monitor the health of drug addicts, while police simultaneously control them through investigation, distribution of sterile syringes, support from social servants, and mobile stations.

According to reports from the authorities, these methods are providing encouraging results. They obviously do not completely eliminate the drug addiction problem. They do, however, stabilize the situation by reducing both the commission of related crimes and the spread of AIDS. In Holland, for example, 75 percent of habitual drug addicts have made contact with treatment organizations, compared to only 40 percent during the first part of the 1980s. In the Liverpool region of Mersey, the increase in crime for 1991 was only 6.2 percent, compared

19. Concerning the United States recently, see M. D. Newcomb, Substance Abuse and Control in the United States: Ethical and Legal Issues, 35 Soc. Sci. MEd. 471-79 (1992).

20. Drug Policies in Westem Europe, 1989 Freiburg I. Br. 175 (H.J. Albrecht ed.); Aspects de la situation et de la politique en matiere de drogue en Suisse 38, (Office Federal de la Sante Publique 1989). 
to the average increase of 18.1 percent throughout the United Kingdom. In Italy, where enforcement of health structures has been the main objective under the $1990 \mathrm{law}$, deaths due to heroin overdose have decreased by over 50 percent during the first three months of 1993.

To sum up briefly, the significant trends currently developing in Europe are the following:

(1) a great uncertainty about punishing drug consumers, but a consensus on offering as many chances for treatment of drug addicts as possible and for offering an alternative between punishment and treatment;

(2) increasingly severe punishment for criminal activities linked to drugs through an increase in penalties and seizure of goods and illegal capital, and a strengthening of international cooperation among magistrates and police forces;

(3) a prudent openness toward ways of decriminalization or legalization of drug usage, at least in the case of "light" drugs. For example, in addition to the traditional tolerance, Holland, Hamburg and Lower Saxony in Germany, and Switzerland recently considered the adoption of different criminal policies which do not exclude legalization of drugs. And, an item on the agenda of the Italian Chamber of Deputies even proposed "a discussion at the international level concerning the effectiveness of the strategies for containment performed so far and possible alternative hypotheses."

In the European Community, various organizations stress the priority of assistance given to drug addicts at risk. ${ }^{21}$ However, the official Community policy remains that expressed by the European Parliament in its Resolution of May 13, 1992, which states that it "does not think that legalization is a feasible solution to the problem of drugs."

21. For example, the "European Plan for the Fight Against Drugs," promulgated by the Pompidou Group on May 19, 1989 was approved by the European Council in Rome on December 14, 1990, and by the European Community Cabinet on November 13, 1992. 